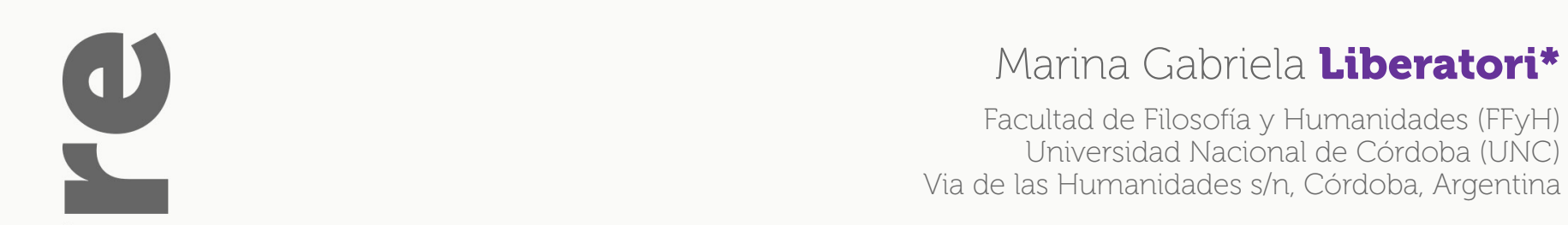

marinaliberatori@gmail.com

\title{
A mi hijo lo eligió dios. \\ Un análisis sobre las moralidades en \\ torno a muertes violentas en villa La Tela (Córdoba-Argentina)
}

\author{
My son was chosen by god. An analysis on the \\ moralities around violent deaths in La Tela slum \\ (Córdoba-Argentina)
}

\section{RESUMEN}

En este artículo busco reflexionar, etnográficamente, sobre diferentes moralidades configuradas en torno a una muerte acontecida en una villa de Córdoba. Ludo Hernández era un joven de 18 años quien era acusado de incurrir en prácticas delictivas tales como robos, consumo y venta de drogas, entre otras. Murió asesinado el 29 de diciembre de 2010. A partir de allí los vecinos de La Tela construyeron diversos relatos sobre esta muerte; muchos de ellos vinculados con cuestionamientos morales relacionados con su conducta, con la educación recibida por su familia, y por consiguiente, con la reputación de la misma. Su madre, por su parte, intentaba "limpiar" la memoria del muerto, a la vez que canalizar el sufrimiento. Intentaré reconstruir las diferentes explicaciones en torno a esta muerte, para ello compararé la muerte de Ludo Hernández, con la de otro joven quien también fue asesinado en la villa, pero en un contexto completamente diferente, puesto que era considerado por sus vecinos como un "chico bueno" y por tanto, su muerte fue llorada y considerada "injusta".

Palabras Clave: Muerte - Moralidades - Villa - Apariciones sobrenaturales - Prácticas delictivas

\begin{abstract}
In this article I propose an ethnographic reflection about different moralities configured around a death happened in a slum in Cordoba on December 2010. Ludo Hernández was a young man who was accused of stealing, using and selling drugs, among others criminal practices. He was killed on December 29, 2010. Then the neighbours of La Tela built stories about this death; many of them about moral questions related to his behaviour, to the education received by his family, and therefore, to the reputation of them. His mother tried to "clean" the memory of Ludo, and at the same time, to face suffering. In this sense, I will try to reconstruct the different explanations around this death. I will compare the death of Ludo Hernández, with the death of another young man who was also murdered in La Tela, but in a completely different context, since he was considered as a "good boy" by his neighbors, so his death was mourned and considered "unfair".
\end{abstract}

Keywords: Death - Moralities - Lum - Supernatural apparitions - Criminal practices

* Doctora en Ciencias Antropológicas, Antropología cultural por la Universidad Nacional de Córdoba. Docente asistente simple en Licenciatura en Antropología en Universidad Nacional de Córdoba (FFyH-UNC). Becaria pos doctoral del CONICET- IDACOR CV: https://ar.linkedin.com/in/marina-liberatori-085a2238. 


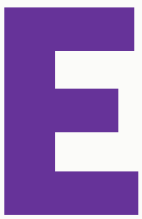

n este artículo busco reflexionar, etnográficamente, sobre diferentes moralidades configuradas en torno a una muerte acontecida en una villa de Córdoba en diciembre de 2010. Partiré de la noción de muerte como un hecho social que produce sentido en la vida de los familiares, amigos y allegados del muerto. Das (2007) nos orienta para pensar en esto como un acontecimiento extraordinario que quiebra la vida de las familias de los muertos; para esta autora las palabras, los discursos que se erigen fuera del ámbito de lo cotidiano sirven como modo de análisis de las situaciones sociales. Así, estos sucesos disruptores de lo ordinario nos permiten analizar etnográficamente ciertos sentidos morales que aparecen en la comunidad. En este caso, se trata de una muerte con un trasfondo violento, aparentemente, por "ajuste de cuentas"1 que desató diversas explicaciones por parte de allegados al muerto y medios de comunicación locales.

Ludo Hernández ${ }^{2}$ era un joven de 18 años que vivía en La Tela, una de las villas más grandes y antiguas de la ciudad. Este muchacho, al igual que sus hermanos, despertaba algunas sospechas en la villa por causa de ser acusado de incurrir en ciertas prácticas delictivas tales como robos, consumo y venta de drogas, entre otras. Murió asesinado el 29 de diciembre de 2010 por el impacto de una bala, a dos cuadras de su casa. A partir de allí los vecinos de La Tela construyeron diversas explicaciones sobre esta muerte; muchas de ellas vinculadas con cuestionamientos morales relacionados con su conducta, con la educación recibida por su familia, y por consiguiente, con la reputación de la misma. Veremos también como su madre, por su parte, construyó su relato en base a cuestiones sobrenaturales que permitieron contrarrestar las acusaciones morales y de alguna manera "limpiar" la memoria del muerto, a la vez que canalizar el sufrimiento. En este sentido, intentaré reconstruir las diferentes versiones en torno a esta muerte, como así también las diversas moralidades que se juegan en las mismas, para ello es necesario comparar la muerte de Ludo, con la muerte de otro joven acontecida en la villa. En este caso, a diferencia de Ludo, el muerto era considerado un "buen chico" puesto que "iba a la escuela y no robaba", por tanto, su muerte es considerada inmerecida por los vecinos. Cabe preguntarnos entonces ¿En qué medida la trayectoria delictiva de los muertos en villa La Tela se articula con las moralidades que se construyen en torno a esas muertes? ¿Cómo se vinculan las acusaciones morales hacia los jóvenes muertos con los reclamos de justicia por parte de sus familias?

\section{Vivir en villa La Tela.}

Existen en Argentina ciertos prejuicios que recaen sobre las personas que habitan en villas y barrios empobrecidos. En este sentido, Puex (2003) establece que las "villas miseria" han sido señaladas como portadoras del mayor foco de violencia urbana en los últimos tiempos. Esta

1 De ahora en adelante, el uso de comillas es para referirme a expresiones que relativizo o ironizo y también para referirme a las categorías teóricas. Asimismo usaré las cursivas entrecomilladas para referirme a las categorías nativas.

2 Este y todos los nombres de personas que aparecen en este escrito son ficticios para preservar la integridad e intimidad de quienes me ayudaron durante tantos años en este proceso de investigación que dio sustento a mi tesis de maestría y doctorado. 
autora llama "territorialización" al proceso por medio del cual se estigmatiza a un determinado lugar dentro del espacio urbano y se realizan en su contra prácticas discriminatorias por parte de autoridades públicas y del resto del sistema social. Guber (2007) sostiene que la figura de las personas que habitan en villas suele caracterizarse por su anomia, carencia de reglas e inmoralidad. La autora, a partir de una investigación etnográfica realizada en una villa en Buenos Aires, concluye que, muchas veces, las personas que residen en villas comparten la mirada que los no villeros tienen sobre estos lugares. A su vez, Guber (2007) explica también que el hecho de ser residentes sin derechos, sumado a las incertidumbres de la vida diaria, fomenta la imagen que la población general y los propios villeros construyen sobre sí mismos. En el contexto local de Córdoba, desde el estado provincial se vienen aplicando, desde el año 2003, políticas de seguridad llamadas "de tolerancia cero y mano dura". Estas políticas implementadas en ese año por el gobernador apuntan, entre otras cosas, a prevenir el delito antes de que acontezca. De esta manera, se previó un aumento de la cantidad de policías circulando por las calles. Además existe un "código de faltas" actualmente devenido en "código de convivencia" que permite a la policía detener a personas según ciertos artículos que se encuentran en dicho código. En la práctica eso se traduce en detenciones masivas principalmente de jóvenes varones provenientes de villas y barrios empobrecidos que se encuentran circulando por otros sectores de la ciudad, como el centro u otros barrios. De esta manera, siguiendo a Vianna (2007) la policía se convierte en un "sujeto clasificador" que elabora distintas clasificaciones sobre los jóvenes que asumen esas categorías, convirtiéndose en "sujetos clasificados". Se vuelve interesante la etnografía de esta autora para pensar en los procesos y las categorizaciones que utiliza la policía para clasificar a los sujetos que se alejan de la norma. Vianna analiza cómo la policía en Brasil es el agente al que se le atribuye la capacidad de control y organización del espacio urbano por lo que está legitimado para reconocer a los "menores potencialmente peligrosos" para la sociedad y accionar sobre ellos.

La Tela es una de las villas más grandes y más antiguas de Córdoba. Se encuentra ubicada en la zona oeste de la ciudad y según el INDEC ${ }^{3}$ 2015, tiene una población que alcanza las 12.000 personas aproximadamente. Comparte ciertas características con otras villas del país: la precariedad de las condiciones habitacionales y la ilegalidad de los terrenos ocupados. Se fue conformando en los años '70, década en la que comenzó, en América Latina, un proceso de modernización y reorganización tanto de las estructuras económicas como de las relaciones sociales y la vida cotidiana (Lechner, 1998). Por estos años, en Argentina se desencadenaron procesos de exclusión vinculados principalmente con transformaciones producidas en el mercado de trabajo. Estos cambios en el sector laboral se relacionan con empleos poco estables, desempleo y la consecuente exclusión de vastos grupos sociales del mercado de consumo (Isla y Míguez, 2003 y 2010). A su vez, La Tela registró un importante crecimiento poblacional debido a la llegada masiva de habitantes expulsados de barrios aledaños y de otros asentamientos cercanos, durante la crisis que azotó a Argentina a comienzos de la última década. La mayoría de las personas que allí habitan tienen empleos informales y también

3 Sigla que refiere al Instituto Nacional de Estadísticas y Censos de Argentina. 
reciben algún tipo de plan social. ${ }^{4}$ En general, los hombres, con los que he conversado, trabajan en el sector de la construcción, como guardias de seguridad en fábricas o juntando cartones y papel en sus carros. Mientras que las mujeres lo hacen en casas de familia como empleadas domésticas, lo que se dificulta, muchas veces, porque no tienen con quién dejar a sus hijos. También es bastante común que la gente improvise en sus viviendas algún negocio de venta de artículos y comestibles.

Realicé trabajo de campo en La Tela desde marzo de 2009 hasta junio de 2012 ininterrumpidamente, y eso dio como fruto mi tesis de maestría en la que trabajé sobre los sentidos que se construían en la villa en torno al miedo y al peligro. Mi objetivo era invertir el lente desde donde se miraba, desde las clases más acomodadas, a la problemática social de la "inseguridad", siempre vinculada al delito y a este último con los sectores pobres de la ciudad. Luego entre marzo y noviembre de 2015 retomé el campo para profundizar sobre los sentidos sobre el mal, las experiencias sobrenaturales y prácticas espirituales con algunos "santos populares" como San La Muerte y Pombagira. Estos santos de "moralidad ambigua" - puesto que podían movilizar tanto el mal, como el bien- eran vinculados con aquellos vecinos que en algún momento de sus vidas habían realizado prácticas ilegales como parte de sus economías. Así, analicé las relaciones sociales e intercambios recíprocos entre estos santos, sus devotos y los vecinos que los señalaban como "malos", para la tesis de doctorado.

Apenas empecé a trabajar en La Tela advertí que se construía allí una "configuración social" (Elias, 2009) entre los vecinos "buenos y los malos" (Liberatori, 2014 y 2016). Así, quienes se consideraban en el primer grupo eran personas que intentaban alejarse de la imagen estigmatizada que se constituye socialmente sobre las personas que viven en villas y barrios empobrecidos. Estos vecinos realizaban juicios acusatorios de maldad (Evans-Pritchard, 2005) hacia los vecinos que en algún momento de sus vidas habían estado relacionados con economías subterráneas e ilegales como el robo y la venta de drogas (Bourgois, 2010). Por este motivo, al principio yo sólo me relacionaba con el primer grupo de vecinos quienes me advertían negativamente sobre esos "otros" con quienes no debía hablar porque "nada bueno me podían decir, además del "peligro" que eso suponía para mí", desde sus propias miradas. Al cabo de unos meses comprendí que necesitaba tener un panorama más completo de la villa y de las relaciones sociales que allí se construían y que necesitaba trascender dicha configuración social de buenos/malos al igual que mis propios prejuicios. Comencé entonces a relacionarme con esos "otros", pese a las advertencias de las personas con quienes yo venía conversando. Como primera medida acepté la invitación que tantas veces me habían realizado un grupo de jóvenes (entre los que se encontraban los hermanos Hernández) que se juntaban en una

4 Los planes sociales refieren a diferentes tipos de subsidios y planes de empleo que el gobierno nacional, provincial o municipal otorga a personas que se encuentran desocupadas o subempleadas. La mayoría de estos planes exigen como contraprestación la realización de tareas en proyectos comunitarios, productivos y también educativos. Por ejemplo, trabajos en comedores, bibliotecas populares, cortaderos de ladrillos, como también realizar cursos en alguna institución educativa. Dicha contraprestación laboral es aproximadamente de cuatro horas la jornada. Estos tipos de planes fueron progresivamente reemplazados por otros subsidios. Primero los programa familia y actualmente la asignación universal por hijo que es la ayuda que la mayoría de los vecinos recibe en Los Vientos. Para más información consultar en www.trabajo.gov.ar 
esquina a tomar una coca cola, ${ }^{5}$ fumar "caretas y porros". ${ }^{6}$ Luego me fui relacionando con las familias de algunos de esos jóvenes.

La familia de Ludo Hernández vive en villa La Tela desde hace 30 años y está conformada por doña Nancy, su madre y ocho hermanos de los cuales Ludo era el sexto. Su padre los abandonó cuando eran pequeños. Después de unos años doña Nancy formó pareja con otro hombre y tuvo a Lucianita, su octava hija.

Yo me la pasé laburando para criar a estos chicos. Y no anduve ni abriendo las piernas, ni choreando ${ }^{7}$, laburé como un burro. (...) Me hice cargo de los ocho yo sola y bueno algunos me salieron bien o están bien ahora como el Ludo y el Darío que también estuvieron presos, pero ahora están trabajando. ${ }^{8}$

Doña Nancy trabajó de empleada doméstica muchos años hasta que formó pareja con el papá de su última hija. Entonces dejó de trabajar y se puso un negocio de venta de comestibles en su casa. Su actual marido trabaja de albañil. Los hijos de doña Nancy tienen "fama"9 de consumir drogas y dedicarse al choreo. Por ese motivo son mal vistos y son receptores de varias críticas y acusaciones morales que no sólo son dirigidas a ellos, sino también a su madre: Parece que a la madre le gustara, sabe que roban, que anduvieron presos y no le importa nada. Es un desastre. ${ }^{10}$ Balbi (2007) sostiene que los valores morales son conceptos cargados de cierto contenido moral relacionado con un contexto social históricamente dado aunque dinámico. Es decir que estarían socialmente condicionados. Tienen que ver con los parámetros normativos que regulan el comportamiento de las personas, pero también con los medios que poseen éstas para comprender el mundo y concebir sus propias prácticas. Podemos decir que los sentidos sobre lo que está bien y lo que está mal en la villa son colectivamente construidos, al igual que la clasificación que realizan entre los vecinos buenos y los malos (Liberatori, 2014 y 2016).

\section{La muerte de Ludo: de apariciones fantasmagóricas}

Él era muy bueno, también estuvo preso como los otros, pero no fue su culpa (...). A mí

5 Bebida gaseosa.

6 Caretas son cigarrillos de tabaco y nicotina, porros de marihuana.

7 Doña Nancy se refiere a que no recurrió a la prostitución, ni a robar para mantener a sus hijos. Ella opone estas actividades ilegales y sobre las que recaen juicios negativos tanto para los vecinos de la villa, como para quienes no viven allí, con trabajar esforzándose como un burro. Es decir que para doña Nancy no sería legítimo recurrir a estas actividades y en caso de haberlo hecho si merecería que sus vecinos la acusen de mala madre. Sin embargo, lo que ella nos plantea es que a pesar de haberse esforzado para salir adelante con sus hijos, algunos le salieron bien y otros le salieron choros. Aunque esto último no lo expresa en este fragmento de entrevista, pero lo ha expresado muy apesadumbrada en otras ocasiones.

8 Entrevista realizada por la autora a Nancy Hernández en octubre de 2010 en villa La Tela Córdoba- Argentina.

9 La categoría "fama" es utilizada por las personas que viven en villa La Tela y refiere a diferentes caracterizaciones que se realizan sobre una persona, generalmente en sentido peyorativo. Así por ejemplo, una persona puede tener fama de "choro" (ladrón), de "chico bueno" (aquel que va a la escuela, no busca pleitos con otros vecinos, no consume drogas). Para una discusión teórica sobre esta categoría se recomienda leer: Pitt-Rivers (1994) y Marques (2002).

10 Entrevista realizada por la autora a Zuny Corola en noviembre de 2009 en villa La Tela Córdoba- Argentina. 
me pueden decir lo que quieran pero a mi hijo lo eligió Dios y eso es por algo... ${ }^{11}$

¿Cómo volver a la villa después de haberme enterado de la muerte de Ludo? Lo supe el 29 de diciembre por casualidad, a partir de una noticia que leí por internet. El diario no decía mucho pero su nombre me quedó retumbando en las pupilas: Ludovico Hernández. No sabía muy bien qué hacer, ¿debía ir o era mejor quedarme y dejar en paz a la familia? Decidí no ir. Días más tarde, charlando con doña Nancy, su madre, me dijo que no debería haberlo dudado, que debería haber ido a despedirme de Ludo para poder quedarme en paz. Vos sos de confianza, como de la familia, me dijo. Fue entonces que comprendí que lejos de incomodar, mi presencia hubiera sido bien recibida debido a la "relación de confianza" que habíamos construido. Sin embargo, como expresé anteriormente, decidí no ir a La Tela y, en cambio, llamar a Naty, una vecina que vivía al lado de los Hernández y con quien yo tenía también una relación de confianza y amistad, para ver si sabía algo. Ella me contó que doña Nancy no estaba en su casa, que debía estar en el hospital Misericordia y que la casa estaba llena de patrulleros y gente que entraba y salía, que ella tampoco se había acercado a dar las condolencias todavía.

Marina: Qué triste Naty, ¿por qué pasan estas cosas? Como cuando lo mataron al Nardo. ${ }^{12}$

Naty: sí, pero no es lo mismo, porque acá al Nardo lo queríamos todos, era un chico bueno que no se metía con nadie. En cambio el Ludo no. ${ }^{13}$

La verdad es que al principio me enojé con Naty por decirme eso, me dolía la muerte de Ludo. Sólo después pude entender todo lo que significaban las distinciones morales sobre esas dos muertes acontecidas en la villa.

Decidí ir a lo de doña Nancy el día dos de enero de 2011. No me interesaba ver a nadie más, sólo quería estar con los Hernández y acompañarlos de cerca. Llovía a cántaros. Al bajar del ómnibus, como pude, fui esquivando los charcos, tenía mucha tristeza y no sabía muy bien cómo manejar la situación ¿qué decir cuándo ningún consuelo es posible? Llegué y estaba Marcio, el hermano mayor, fumando un cigarrillo en la puerta. Me acerqué y nos dimos un abrazo. Estoy destruido, me dijo. Al rato salió Lucianita, la hermanita menor de 5 años. Al verme me interrogó con una sonrisa fresca, ¿vos sabías que a mi hermano Ludo le pegaron un tiro? Le respondí que sí sabía. Me quedé pensando en ese momento sobre la naturalidad con la que los niños procesan los acontecimientos duros de la vida y sobre la violencia cotidiana con la que estas personas conviven todos los días. Una vez conversando con Lucianita me contaba que le tiene mucho miedo a los policías porque ella los ve cuando entran a su casa a los tiros y se llevan a alguien.

Entramos a la casa, doña Nancy recién se levantaba. Nos dimos un abrazo, me hizo pasar a la cocina y puso a calentar agua para el mate. ${ }^{14}$ Me comentó que hoy había podido dormir bien, como nunca. Yo le dije: qué bueno porque lo debía estar necesitando y ella me

11 Entrevista realizada por la autora a Nancy en febrero de 2011 en villa La Tela-Córdoba- Argentina.

12 Me refiero a Nardo Leguizamón otro joven de la villa asesinado en el 2008. Analizaré el caso de esta muerte en comparación con la muerte de Ludo párrafos más adelante.

13 Entrevista realizada por la autora a Naty Corola en enero de 2011 en villa La Tela- Córdoba- Argentina.

14 Bebida a base de yerba mate. 
dijo que sabía que era por causa de que el Ludo la había ayudado. Me contó cómo había sido ese día y que muchos de sus vecinos ni siquiera se habían acercado a darle el pésame. La noté dolida por ese motivo.

Nancy: Él era muy bueno, también estuvo preso como los otros, pero no fue culpa suya. Lo agarraron esa vez porque la policía buscaba al Danilo (otro de sus hermanos) porque había robado un colectivo con un arma y cayó el Ludo. Lo corrieron a los tiros y estuvo seis meses preso, pero fue culpa del Danilo. A mí me pueden decir lo que quieran pero yo sé que a mi hijo Ludo lo eligió Dios para llevárselo y eso es por algo, porque él era bueno. ${ }^{15}$

Pasada una semana regresé a la casa de doña Nancy, ella estaba sola y me agradeció la compañía, se notaba que necesitaba hablar de lo que había sucedido.

Él sabía lo que le iba a pasar, yo últimamente lo veía muy cambiado. Estaba como más maduro. Dejó todo limpio antes de irse. Lavó toda su ropa, las zapatillas, todo. Como si hubiera sabido, porque para mi él sabía que dios lo iba a llevar. Te digo que él sabía lo que le iba a pasar porque cuando le pegaron el tiro él le dijo a su hermano Alex: yo esto lo soñé y el Alex le preguntó: ¿y cómo termina el sueño? Pero el Ludo no dijo nada, él ya sabía que se iba. ${ }^{16}$

Ludo murió el 29 de diciembre de 2010. Según dice su familia, por causa de un tiro que le propinó un desconocido. Doña Nancy afirma que ese día Ludo tenía un curso en el $\mathrm{ClC}^{17}$ para empezar a trabajar en una cooperativa de la villa. Pero en vez de irse para el curso, Ludo y su hermano Alex se fueron para otro lado por causas desconocidas para su familia.

Esa noche estábamos todos en el hospital, acá en casa sólo se habían quedado el Alex y el Danilo cuidándola a la Lucianita. Yo había dejado prendida una velita y el Alex dice que como a la una de la mañana entró un aire y la velita se apagó. Yo digo que ese fue el Ludo que vino y les avisó que se había ido, porque si te fijas él se murió a esa hora, a la una de la mañana. Pobre hijo mío me lo mataron, pero yo digo que el mal va y vuelve y los que lo mataron van a tener su castigo. ${ }^{18}$

Todas las veces subsiguientes que volví a lo de los Hernández, doña Nancy me llamaba aparte para conversar sobre Ludo. Según me contaba ella sentía su presencia, incluso me decía que Ludo la cuidaba y ayudaba a estar fuerte para sobrellevar los chismes de otros vecinos sobre la muerte de su hijo. Una vez me contó que la noche anterior Ludo había estado en la casa:

15 Entrevista realizada por la autora a Nancy Hernández en enero de 2011 en villa La Tela- Córdoba- Argentina.

16 Entrevista realizada por la autora a Nancy Hernández en enero de 2011 en villa La Tela- Córdoba- Argentina.

17 Los Centro Integradores Comunitarios $(\mathrm{ClC}$ ) son dependencias municipales que suponen la integración y coordinación de políticas de Atención Primaria de Salud y Desarrollo Social. Cuentan con un equipo técnico constituido por trabajadores sociales, psicólogos y médicos generalistas, que trabaja en coordinación con los vecinos.

18 Entrevista realizada por la autora a Nancy Hernández en enero de 2011 en villa La Tela- Córdoba- Argentina. 
A las tres de la mañana me desperté porque había ruidos en la cocina y se sentía como olor a milanesa, yo pensé que era alguno que se estaba cocinando pero cuando fui a ver no había nadie y entonces yo supe que era él Marina, porque las milanesas eran su comida preferida. ${ }^{19}$

En otra oportunidad fue Caro, una de las hermanas de Ludo, la que me comentó que había visto una sombra que pasaba justo cuando otros de sus hermanos se estaban peleando y que, en ese momento, ellos dejaron de agredirse. Según doña Nancy dios permitía que Ludo siguiera en contacto con su familia debido a la bondad que había en su alma, pese a lo que podían decir los vecinos, pero a la vez afirmaba que Ludo no podía descansar en paz porque su asesino seguía suelto. Puede decirse que "los muertos retornan sistemáticamente al mundo de los vivos para pedir, para dar y también para ayudar" (García Sotomayor, 2014, p. 266). Esta autora analiza cómo las fronteras entre la vida y la muerte se vuelven difusas y esto permite que puedan establecerse relaciones de reciprocidad entre los vivos y los muertos. Así, mientras Ludo puede contribuir con la paz familiar evitando una pelea, acompañar a su madre y cuidar el hogar, su madre lo alumbra todos los lunes poniendo una velita al pie de una foto colocada a modo de altar sobre un mueble de la cocina.

Quisiera destacar dos cosas en este apartado. Por un lado, la necesidad de doña Nancy de demostrar la bondad de Ludo, en contraposición con las acusaciones de maldad por dedicarse al choreo por parte de sus vecinos, quienes tienen otra versión sobre su muerte como veremos más adelante.

Gran parte de las personas terminan asociando que, quien mal anda esto es en el delito y/o en las drogas-, mal acabará, aceptando ese final predestinado por el comportamiento de alguien. Podemos observar también cómo existe en esta frase una responsabilización individual por la opción de vida que cada uno adopta (Bermúdez, 2011 p. 161).

Siguiendo a Bermúdez se puede observar cómo las muertes violentas son clasificadas y jerarquizadas de acuerdo a las personas que matan y a las que mueren, a los valores morales asociados con las mismas y a los contextos y situaciones donde ocurrieron estas muertes. En la misma línea que Boltanski (1993), esta autora nos ilumina para pensar en cómo muchas veces, se responsabiliza al muerto de su propia muerte. Por su parte, Boltanski (1993) analiza cómo se establece una distribución social y política de las responsabilidades y los costos del sufrimiento. Respecto de las muertes de los jóvenes que habitan en sectores populares, podríamos pensar que, desde la perspectiva de las personas que no viven allí, desde el tratamiento de estos acontecimientos en los medios locales y desde ciertas políticas estatales, se tiende a cargar de responsabilidades a los muertos y a sus familiares. Esto es porque la imagen negativa que recae sobre la figura de los moradores de villas, hace que ciertas muertes sean consideradas más injustas que otras. Y en este sentido, ciertas vidas con más valor que otras. Por el contrario, si fue dios el que se llevó a Ludo, como afirma su madre, quiere decir que el alma del joven era "buena" por lo que puede limpiarse su memoria y, de alguna manera, ajusticiar las acusaciones

19 Entrevista realizada por la autora a Nancy Hernández el febrero de 2011 en villa La Tela- Córdoba- Argentina. 
morales sobre su trayectoria asociada con el delito. Además si Ludo, como dice su madre, era "bueno" su muerte puede considerarse "inmerecida", y justificada por la voluntad divina. Las experiencias extraordinarias que relata la familia de Ludo acerca de la "presencia" que se advierte en su casa, es también una validación de su "bondad" puesto que aún después de muerto, continúa ayudando a sus seres queridos en las vicisitudes de la cotidianidad.

De alguna manera, es necesario para la familia de Ludo, confiar en la bondad de su alma que se manifiesta en esta posibilidad de aparecer para brindar apoyo a su familia. Como vimos el asesinato de Ludo fue producido en un confuso episodio que pone en tela de juicio la moralidad del muerto, ya que se lo acusa de haber estado robando. Por esta razón, es difícil para doña Nancy, su madre, poder acudir a la justicia para reclamar que se esclarezca la muerte de su hijo. Como veremos las acusaciones de los vecinos de que sus otros hijos estaban también involucrados en ese robo que terminó con la vida de Ludo, la detiene para reclamar justicia. Asimismo, la demanda de justicia se vuelve compleja, porque la sospecha de que Ludo estuviera robando cuando fue asesinado lo señala como delincuente y por tanto su muerte era esperable en ese universo de posibilidades. Esta mirada compartida por muchos de los vecinos de La Tela y por los medios de comunicación, lleva implícito el mensaje de que hay muertes que se justifican más que otras, que merecen justicia más que otras. Como si el hecho de haber cometido un crimen negara al muerto la posibilidad de justicia, como si el delito cometido tuviera más valor que la propia vida humana. En este escenario, doña Nancy y su familia encontraron consuelo en la justicia divina que puede acreditar la bondad de Ludo a pesar de las sospechas de sus vecinos y cuya prueba más contundente es el acercamiento sobrenatural del muerto.

Por otra parte, estas experiencias sobrenaturales de la familia de Ludo me enfrentaron como etnógrafa a un dilema metodológico acerca de cómo abordarlas, controlando mi propia racionalidad que a veces me obnubilaba el sentido de los relatos; pero a la vez sin perder el "rigor científico". Fue así como tuve que recalcular el campo, reposicionarme frente a esas experiencias intangibles y distanciarme de las maneras más objetivistas de pensar el trabajo de campo. De esta manera, tuve que trascender aquellas concepciones que imponen cierta distancia con las vivencias de las personas con las que trabajamos, como si estuviéramos escindidos de la gente; como si estas experiencias "de ellos" fueran diferentes de las que tenemos los antropólogos. A la inversa, inspirada en autores como Goldman (2003 y 2006), Favret-Saada (2005); Ingold (2012); Guber (2014) y Tobón (2015) considero que no es posible el conocimiento sin pensarnos como partes de esa urdimbre de relaciones sociales que analizamos para construir los datos que luego formaran parte de nuestras investigaciones. La idea de correspondencia en un espacio tiempo determinado con las personas con las que trabajamos (Ingold, 2012) me permitió correrme de la necesidad de comprobar la veracidad de estos relatos y por el contrario, aceptar que para la familia de Ludo su "presencia" en la casa de los Hernández "era real". En relación con lo que planteo aquí, Tello Weiss (2016) quien analiza apariciones fantasmagóricas en un ex centro clandestino de detención de la última dictadura militar en Argentina, propone que, 
quizás sea esa, justamente, la virtud de los fantasmas y sus historias: enfrentarnos a una tensión ontológica y epistemológica tal que invite a apreciar nuevamente, al decir de Geertz (1992), los usos hermenéuticos de la conmoción y la confusión. Escurridizas como el propio fenómeno, las estrategias de abordaje y de escritura etnográfica sobre la temática, invitan también a una revisión de los modelos canónicos de hacer y escribir etnografía (Tello Weiss, 2016, p. 19).

Por tanto, como dije, no estaba yo interesada en validar esos relatos en relación con estas experiencias sobrenaturales, sino más bien analizar cómo eran significadas por ellos en su vida diaria, como forma de canalizar el sufrimiento y revertir las acusaciones morales de sus vecinos. Así, pude observar cómo las fronteras entre lo cotidiano y lo extraordinario, entre la vida y la muerte se tornaban porosas, y se volvía gratificante cualquier tipo de contacto con el ser querido muerto.

\section{Los vecinos, los medios masivos y la moralidad del muerto.}

Días después de visitar a los Hernández decidí ir a la casa de doña Hortensia, una de las primeras vecinas que comencé a visitar ni bien iniciaba mi trabajo de campo. Allí estaba uno de sus hijos y comenzamos a conversar de lo acontecido:

Hortensia: estamos de velorio por acá, viste que se ahorcó un chico de la manzana 10 y hace unos días lo mataron a uno de los chicos Hernández.

Marina: si qué tristeza.

Henry: es por la droga todo eso.

Hortensia: es así la droga nos está matando a los chicos.

Henry: hacen cualquier cosa por conseguir droga. El Ludo les había choreado a los que les dispararon. Parece que él y el hermano que iba con él, el Alex, lo habían apuntado con un arma que no tenía balas y los otros se dieron cuenta y le pegaron dos tiros. Uno le pasó por el costado de la cara al Alex (hace la seña) y el otro le dio al Ludo. Encima casi caen los traficantes de acá.

Marina: Ah ¿cómo?

Henry: y porque la Chelco, la novia del Danilo (otro de los hermanos de Ludo) está metida también en los choreos, ella les vende droga a los de afuera y los de acá les chorean la mercadería que compran". ${ }^{20}$

La Chelco, novia de Danilo Hernández, es una chica de 32 años que tiene "fama" en la villa de vender droga. Doña Nancy muchas veces me ha expresado su descontento porque dice que la Chelco lo ayuda a Danilo a organizar robos, ya que le consigue armas y le presta su moto:

Ayer el Danilo me mostró un "regalito" porque así me dijo: mirá el regalito que consiguió la Chelco. Era un arma, lo supe sin abrir el paquete por

20 Entrevista realizada por la autora a Hortensia y Henry Moreno en enero de 2011 en villa La Tela-Córdoba-Argentina. 
el peso. Y yo le dije bien clarito al Danilo: dejate de joder con eso, van a terminar mal. ${ }^{21}$

Una de las versiones que circulan en la villa sobre la muerte de Ludo es que él robó la droga que unos jóvenes de un barrio vecino le habían comprado a la Chelco. Según esta perspectiva todo era un plan organizado por tres de los hermanos Hernández, la Chelco y dos amigos más. Plan que no salió como esperaban y terminó con la vida de Ludo. Epele (2010) reflexiona sobre las moralidades que se ponen en juego respecto de los sentidos configurados sobre las muertes de los jóvenes implicados con la droga en una villa del Gran Buenos Aires. Así, señala que se produce una naturalización de la muerte de estos jóvenes como si fuera "esperable" que muriesen. Esto aconteció en la villa respecto de la muerte de Ludo, ya que para muchos vecinos era como una especie de profecía auto cumplida por causa de la trayectoria delictiva del muerto que lo enfrentaba a los peligros que supone la misma. Como veíamos anteriormente a partir de los análisis de Bermúdez (2011) "quién mal anda, mal acaba". Estas consideraciones morales entran en conflicto con el dolor que sienten principalmente los familiares y de alguna manera, pone en tensión el duelo público de esa muerte. Así, tal como lo expresó doña Nancy nadie fue a darle las condolencias, motivo por el cual ella quedó resentida con sus vecinos. En este sentido, doña Nancy niega que su hijo haya sido muerto como consecuencia de haber estado relacionado con la droga y el delito. Ella afirma que ese día sus hijos Ludo y Alex tenían un curso en el CIC pero que éste se suspendió por lo que se fueron para el lado de ruta 20 donde viven varios amigos de los chicos. Asegura que Danilo estaba durmiendo en su casa y que nada tuvieron que ver con ningún robo a los clientes de la Chelco. Como vimos, para doña Nancy su hijo Ludo era bueno y aunque algunas veces se había visto envuelto en alguna situación delictiva, la culpa era de los hermanos mayores.

Por su parte uno de los diarios más importantes de la ciudad titulaba así la noticia:

En ajuste, matan de un tiro a un hombre en Villa La Tela. Los Asesinos siguen prófugos. Nadie del entorno de la víctima se atreve a brindar información a la Policía.

La causa fue un ajuste de cuentas. El motivo se desconoce; nadie del entorno de la víctima - ni la víctima misma, antes de morir- quiso decir nada. Lo concreto es que, en Villa La Tela, en el suroeste de la ciudad de Córdoba, un hombre de 18 años fue ejecutado de un balazo. Quedó malherido y murió poco después en el Hospital Misericordia. ${ }^{22}$

La noticia asegura que se trató de un ajuste de cuentas, lo que deja implícito una cierta responsabilidad del muerto sobre su propia muerte. Un "ajuste" significa que alguien cobró venganza de Ludo, dándole muerte. Si cobró venganza es porque antes Ludo tendría que haberle hecho algo que mereciera una venganza. Por otra parte, el diario asegura que no se conocen los motivos ya que nadie quiso hablar, ni siquiera Ludo antes de morir. Lo que me interesa aquí es desentrañar los valores morales que cada relato deja traslucir sobre la muerte de Ludo, como si hubiera sido la marca de un destino que indefectiblemente iba a acontecer,

21 Entrevista realizada por la autora a Nancy Hernández en octubre de 2010 en villa La Tela- Córdoba-Argentina.

22 "Día a Día", Córdoba, Diciembre de 2010. Versión electrónica disponible en: http://www.diaadia.com.ar/content/ en-ajuste-matan-de-un-tiro-un-hombre-en-villa-la-tela. 31 de Diciembre de 2010. 
como si hubiera sido una consecuencia de su trayectoria de vida.

\section{Morir siendo "bueno": la muerte de Nardo.}

¿Qué cuenta como vida vivible y muerte lamentable? (Judith Butler, 2006)

Retomaré la conversación telefónica que mantuve con Naty el día de la muerte de Ludo acerca del asesinato de otro joven de La Tela. Nardo era el segundo de seis hermanos, tenía 17 años y según su madre y otros vecinos con los que conversé sobre este caso, era bueno porque iba a la escuela, no robaba, no se drogaba y no peleaba con nadie. Mono, el hermano mayor, en cambio se dedicaba al choreo y días antes de la muerte de su hermano había robado mercadería a doña Marta, una señora que vende droga con su familia en la villa desde hace algunos años. Uno de los hijos de Marta, el loco Waldo, juró vengarse del Mono y días más tarde le pegó un tiro a Nardo delante de algunos vecinos que pasaban por ahí. Nardo se encontraba en la canchita, lugar al aire libre donde los chicos se juntan a jugar al fútbol, entre otras actividades. Quienes presenciaron el hecho dicen que Waldo le dijo: avísale a tu hermano que el próximo va para él ${ }^{23}$ y disparó. Nardo no murió inmediatamente, fue rescatado por unos amigos y llevado al hospital. Volvió a su casa y falleció una semana más tarde producto de una infección en la herida de bala. Según me contaba Carolina una vecina que acompañó a la familia de Nardo:

El velorio fue muy lindo, todos lo queríamos a Nardo, era un ángel, nada que ver con el hermano. La culpa de todo la tuvo el Mono y sabe muy bien que el tiro no era para su hermano, sino para él. ${ }^{24}$

Nardo estaba por cumplir 18 años, así que su madre resolvió hacer una fiesta a la que asistieron muchos de los vecinos de la villa. El festejo fue una manera de conmemorar al muerto, pero también de acompañar el dolor de la familia que había quedado deshecha. Por otra parte, la justicia ordenó la captura del loco Waldo que se dio a la fuga y colocó un policía para que custodie la casa de esta familia las 24 horas. Esta medida fue tomada por causa de que éste prometió vengarse del Mono. El asesino fue atrapado un año más tarde en la provincia de Santa Fe tras dar muerte a un policía. Actualmente cumple su condena en la ciudad de Córdoba.

"Nardo era un chico bueno que no se metía con nadie, ni andaba en cosas raras", como me expresaron tantas veces los vecinos con los que conversé. En villa La Tela, a diferencia de Ludo, todos lamentaron su muerte, considerándola una "muerte injusta". En primer lugar, por la trayectoria moral intachable de Nardo. En segundo lugar, porque la bala no era para él, sino para su hermano que había provocado la ira de Waldo al robarle mercadería a su madre. Tal vez si a la bala la hubiera recibido su hermano el Mono, otra hubiera sido la historia desde estas representaciones de muertes consideradas "injustas" y muertes "merecidas" (Bermúdez, 2011).

23 Nota de campo, septiembre 2010.

24 Entrevista realizada por la autora a Carolina Moreno en febrero de 2011 en villa La Tela- Córdoba-Argentina. 
Así, como vimos la muerte de Ludo es concebida como una muerte "merecida y esperable" por los vecinos de La Tela, debido a su trayectoria asociada con delincuencia. A su vez, su familia intenta limpiar su imagen destacando atributos de Ludo como la bondad y la obediencia, y trasladando la culpa de sus acciones moralmente condenables a sus hermanos. Tal parece como si el dolor de doña Nancy necesitara de este proceso de "purificación" de la imagen de su hijo para que esa muerte sea llorada socialmente, para borrarle el manto de duda, para que deje de ser una muerte considerada "esperable" y que, por tanto, se torne una muerte "injusta", al igual que la de Nardo. Al fin y al cabo ambos eran jóvenes, más o menos de la misma edad, con toda la vida por delante.

Algunas vidas valen la pena, otras no; la distribución del dolor que decide qué clase de sujeto merece un duelo y qué clase de sujeto no, produce y mantiene ciertas concepciones excluyentes de quién es normativamente humano ¿qué cuenta como vida vivible y muerte lamentable? (Butler, 2006, p. 52).

Seguimos a esta autora para reflexionar sobre la moral y el valor de la vida y de la muerte de los sujetos en la esfera pública. Desde estos aportes se pueden pensar en las diferentes consideraciones que se realizan dentro y fuera de la villa sobre los jóvenes, sus trayectorias morales y los contextos de sus muertes como consecuencia de haberse hecho los malos. Podemos pensar en Nardo y Ludo como sujetos que se construyen en relación a un otro social que los clasifica. Así, uno es considerado "un buen chico que no se mete con nadie", por sus vecinos, mientras el otro es señalado como un "choro". Butler (2006) analiza cómo el duelo se vuelve una cuestión pública permitiendo elaborar una especie compleja de comunidad política. En este sentido, reflexiona en torno a los lazos sociales que nos vinculan con las demás personas. La autora se pregunta quiénes se vuelven personas vulnerables, potenciales de ser víctimas y quiénes nunca lo serán. $Y$ en la misma dirección quiénes se convierten en personas "matables" para la mirada pública, como en el caso de Ludo, y quienes no, como la muerte de Nardo. En estas construcciones se ponen de manifiesto las moralidades que se traducen en clasificaciones sobre lo correcto y lo incorrecto, sobre el bien y el mal y por tanto, en el merecimiento o no de la muerte. Siguiendo a Evans-Pritchard (2005), la muerte es un hecho social que pone de manifiesto las relaciones sociales que se establecen en un espacio determinado. En este sentido, Elias (2009) se pregunta cómo es que las personas se encuentran ligadas y son interdependientes unas de otras. Entonces desarrolla un modelo teórico de "configuraciones sociales" que le sirve para comprender las relaciones entre pares que han sido considerados como antagónicos por estudios anteriores, como por ejemplo, "individuo y sociedad". Lo que intenta Elias es comprender las relaciones entre éstos que se fueron dando a través de la historia y de diferentes procesos sociales que los vuelven mutables y en un fluir continuo. El autor aplica este modelo en configuraciones de gran escala como los Estados-Nación, pero también para analizar las interdependencias de pequeñas escalas como su trabajo en Winston Parva. Para Elias las ligaciones emocionales van cambiando conforme lo van haciendo las sociedades y los grupos, pero lo que no se modifica es que las personas son 
interdependientes entre sí. Este aporte de Elias es iluminador para pensar en la configuración que se construye en La Tela entre jóvenes buenos que no merecen morir y jóvenes delincuentes. Podemos ver cómo la acusación moral de ser un "choro" imposibilita a la familia a reclamar justicia por esa muerte. Por el contrario, si el muerto es un "chico bueno" su familia no tiene impedimentos para aspirar a que el culpable de esa muerte sea castigado.

En La Tela ambos muertos eran jóvenes y ambos fueron llorados por sus familiares. Sin embargo, sus muertes no significaron lo mismo para la comunidad moral de la villa. Sobre la muerte de Ludo recae un manto de duda por lo que muchos vecinos de la villa no fueron a darle el pésame a doña Nancy. Por el contrario, en el caso de Nardo todos en la villa sabían que esa bala que le dio muerte no era para él, sino para su hermano, que andaba en el choreo. Por tanto, Nardo, quien era bueno, se convirtió en una víctima y su muerte mereció ser lamentada y llorada por los vecinos. Ludo, en cambio, a través de su muerte, puso fin a una trayectoria de vida moralmente condenable por los vecinos. Estas moralidades negativas no sólo son configuradas en torno a la imagen del muerto (y en este caso a la de sus hermanos varones), sino también y principalmente a doña Nancy. En este sentido, es quizás la figura de la madre la que está puesta en juego a la hora de juzgar la moral de la familia y el mal que pueden ocasionar sus hijos. Las madres son las principales educadoras y transmisoras de valores morales y las responsables de que sus hijos les salgan derechitos. Siguiendo a Bermúdez:

la figura de la madre se establece de manera significativa para entender estas muertes, porque se le confiere a la misma cierta legitimidad para reclamar y pedir justicia en el espacio público -casi- a pesar de todo, incluida la 'inmoralidad' que podría representar su hijo, el dolor de una madre es igual para todas, sea un choro (ladrón) el hijo o no; o bien, una madre es una madre, son expresiones expresadas habitualmente por todos los interlocutores. Sin embargo, existe un aspecto ambiguo aquí por la "responsabilización" de las madres, por la educación que se les debería haber dado a sus hijos (Bermúdez, 2011, p. 106).

Lo que se juzga de una madre es no haber evitado que sus hijos anden mal, es decir que no sean buenitos. Desde estas visiones, el control de una madre es lo que aleja a los jóvenes de los peligros que supone andar con malas juntas, involucrados en actividades delictivas que además de reforzar los estigmas construidos sobre los que viven en villas y barrios empobrecidos, involucra a los jóvenes con un contexto autodestructivo que los enfrenta con la cárcel y la muerte. Por tanto, doña Nancy tenía necesidad de limpiar la memoria de su hijo para que su muerte pudiera ser llorada en la villa, como la de Nardo y considerada merecedora de justicia, pero también para limpiar su imagen de madre, juzgada negativamente por algunos de sus vecinos.

\section{Conclusiones}

La muerte de Ludo movilizó una serie de moralidades negativas en la villa en relación 
con la trayectoria del muerto, pero también extensible al resto de su familia, especialmente a su madre, a quien se responsabilizó de no haber hecho nada para evitar esta muerte. Es decir no haber bien-criado a sus hijos para que se mantuvieran alejados de "las malas juntas" y del mundo del delito. Como establece Balbi (2007) los valores morales se encuentran fuertemente vinculados con un contexto socio-histórico determinado, con una comunidad con la que se comparten sentidos siempre fluctuantes acerca de lo correcto, e incorrecto, del bien y del mal. En este sentido, cuando comencé a trabajar en la villa advertí que se construía allí una configuración social entre los vecinos "malos y buenos" (Elias, 2009). Desde el punto de vista de estos últimos, la maldad estaba relacionada con ciertas prácticas económicas subterráneas e ilegales tales como el "choreo" y la venta de drogas y asociada con la mirada estigmatizada que otras personas de clases más favorecidas construyen sobre "los villeros". Así, Ludo era acusado de "andar mal" debido a su "fama de choro y drogadicto" y por tanto su muerte condensó una serie de acusaciones morales en la villa que la hicieron ser considerada "esperable". Por el contrario, la muerte de Nardo, otro joven morador de La Tela que era asociado con la bondad por causa de su conducta, -iba a la escuela, no consumía drogas, no peleaba con otros jóvenes, entre otras cosas-, fue llorada y lamentada públicamente.

La familia de Ludo, por su parte, necesitaba limpiar la memoria del muerto para que su muerte pudiera ser considerada lamentable, al igual que la de Nardo. Los valores morales contrapuestos asociados a las trayectorias de los muertos tuvieron también correlato en las búsquedas de justicia de ambas muertes. Así, en el caso de Nardo, su familia consiguió que se encarcelara al asesino tras un largo juicio. Sin embargo, la familia de Ludo se mantuvo alejada de los organismos de justicia y sólo se limitó a responder las preguntas que la policía les realizaba de vez en cuando. De esta manera, puede decirse que la legitimidad de la búsqueda de justicia estaba asociada, en la villa, con dichas moralidades vinculadas con el muerto y su familia, pero también con la manera de morir. Esto es, en el caso de Nardo fue alcanzado por una bala que iba como amenaza para su hermano, quien había robado a un vecino. En cambio, en el caso de Ludo las versiones que circulaban en la villa y en medios de comunicación de la ciudad, tenían que ver con un "ajuste de cuentas" ya que el muerto estaba, supuestamente, involucrado en robos.

En este sentido, aunque la familia de Ludo no reclamó justicia por su muerte, si intentó "purificar" su memoria a partir de la afirmación de bondad del muerto. La bondad de Ludo podía comprenderse desplazando las culpas por su trayectoria delictiva hacia sus hermanos. Su madre, doña Nancy enfrentaba las acusaciones morales que le recaían, por parte de algunos vecinos argumentando que ella había tenido que hacerse cargo sola de 8 hijos y aunque esto no la eximía de la "responsabilidad", si explicaba por qué no había podido "criar a sus hijos derechito" tal y como le señalaban en La Tela. Por otra parte, su dolor de madre pudo ser aliviado a partir de considerar que fue dios quien eligió a Ludo por ser, justamente, un alma buena. La bondad del muerto y las "experiencias sobrenaturales" que tuvo su familia a partir de su muerte, pusieron en tensión las fronteras entre la vida y la muerte volviéndolas porosas. Es así como Ludo podía comunicarse con su familia y ayudarlos en la cotidianidad de las situaciones hogareñas. Así, su familia podía sostener la imagen de bondad que Ludo requería para que su 
muerte pudiera ser lamentada, a pesar de haber sido "esperable" por los vecinos.

A su vez, estas "experiencias extraordinarias" que aparecían en los relatos de la familia de Ludo me empujaron, como etnógrafa, a tomar un rumbo metodológico que me permitiera asirlas, aprehenderlas, asimilarlas y comprender que para la familia Hernández esto no se vislumbraba como "una creencia" sino que era parte de su realidad. Por tanto, debía evitar buscar explicaciones desde mi propia racionalidad, y no caer en el reduccionismo de intentar "verificar" la veracidad de estos relatos. Por el contrario, me reposicionaron en el campo para mirarme como parte de esa urdimbre de relaciones sociales que co-construimos con las personas y me permitieron conectarme con mi propia emocionalidad respecto del dolor que me causaba esa muerte por haber establecido, a través del tiempo, una relación estrecha de confianza y amistad con la familia de Ludo.

\section{Referencias bibliográficas}

BALBI, Fernando Alberto. De leales, desleales y traidores: Valor moral y concepción de política en el Peronismo. Buenos Aires: Antropofagia, 2007. 400p.

BERMÚDEZ, Natalia. "Y los muertos no mueren": Una etnografía sobre clasificaciones, valores morales y prácticas en torno a muertes violentas (Córdoba, Argentina). Alemania: Editorial Académica Española, 2011. 253 p.

BOLTANSKI, Luc. La souffrance à distance: Morale humanitaire, médias et politique. Paris: Editions Métailie, 1993. 288p.

BOURGOIS, Philippe. En busca de respeto: Vendiendo crack en Harlem. Buenos Aires: Siglo Veintiuno, 2010. 421p.

BUTLER, Judith. Vida Precaria: El poder del duelo y la violencia. Buenos Aires: Paidós, 2006. $181 \mathrm{p}$.

DAS, Veena. Life and words: violence and the descent into the ordinary. Berkeley: University of California Press, 2007. 296p.

ELIAS, Norbert. El proceso de la civilización: Investigaciones sociogenéticas y psicogenéticas. Ciudad de México: Fondo de Cultura Económica, 2009. 674p.

EPELE, María. Sujetar por la herida: Una etnografía sobre drogas, pobreza y salud. Buenos Aires: Paidós, 2010. 296p.

EVANS-PRITCHARD, Edward Evan. Bruxaria, oráculos e magia entre os Azande. Rio de Janeiro: Zahar, 2005. 253p.

FAVRET-SAADA, Jeanne. Ser afetado. Tradução de Paula Siqueira. Cadernos de campo. São Paulo, v. 13, n. 13, p. 155-161, 2005.

GARCÍA SOTOMAYOR, Cecilia. La vida de los muertos. Una etnografía sobre relaciones 
sociales barriales y espacialidad en un barrio de Córdoba. En: BERMÚDEZ, Natalia y PREVITALI, María Elena (Orgs). Merodeando la ciudad: Miradas antropológicas sobre espacio urbano e "inseguridad" en Córdoba. Córdoba: Ediciones del Idacor, p. 241-269, 2014. 273p.

GOLDMAN, Marcio. Alteridade e experiência: antropologia e teoria etnográfica. Etnográfica. Lisboa, v. 10, n. 1, p. 161-173, maio 2006.

GOLDMAN, Marcio. Os tambores dos mortos e os tambores dos vivos. Etnografia, antropologia e política em Ilhéus, Bahia. Revista de Antropologia da USP. São Paulo, v. 6, n. 2, p. 423-444, 2003.

GUBER, Rosana. Identidad social villera. En: BOIVIN, Mauricio y ROSATO, Ana (Eds.). Constructores de otredad: una introducción a la Antropología Social y Cultural. Buenos Aires: Antropofagia, p. 115-124, 2007. 350p.

GUBER, Rosana (Comp.). Prácticas etnográficas: Ejercicios de reflexividad de antropólogas de campo. Buenos Aires: Instituto de Desarrollo Económico y Social Miño y Dávila, 2014. 223p.

INGOLD, Tim. Ambientes para la vida: Conversaciones sobre humanidad, conocimiento y antropología. Montevideo: Trilce, 2012. 81p.

ISLA, Alejandro y MÍGUEZ, Daniel (Orgs.). Heridas urbanas: Violencia delictiva y transformaciones sociales en los noventa. Buenos Aires: Ed. de las ciencias, 2003. 336p.

ISLA Alejandro y MIGUEZ, Daniel. Entre la inseguridad y el temor. Instantáneas de la sociedad actual. Buenos Aires. Paidós, 2010, 169 p.

LECHNER, Norbert. Nuestros miedos. Perfiles latinoamericanos. Ciudad de México, v. 7, n. 12, p. $179-198,1998$.

LIBERATORI, Marina. El mal que puede volver: Antropología de los sentidos sobre el mal, experiencias con santos populares y relaciones sociales en villa La Tela (Córdoba). Tesis (Doctorado en Ciencias Antropológicas). Facultad de Filosofía y Humanidades, Universidad Nacional de Córdoba, Córdoba, 2016. 180p.

LIBERATORI, Marina. Y sí vivo en una villa... Una etnografía sobre los miedos y peligros en villa La Tela de Córdoba. Tesis (Maestría en Antropología). Facultad de Filosofía y Humanidades, Universidad Nacional de Córdoba, Córdoba, 2014. 150p.

MARQUES, Ana Claudia. Intrigas e questões: Vingança de família e tramas sociais no sertão de Pernambuco. Rio de Janeiro: Relume-Dumará, 2002. 352p.

MíGUEZ, Daniel. Delito y cultura: Los códigos de la ilegalidad en la juventud marginal urbana. Buenos Aires: Biblos, 2008. 254p.

PITT-RIVERS, Julian Alfred. Un pueblo de la Sierra Grazalema. Madrid: Alianza Editorial, 1994. 261p.

PUEX, Nathalie. Las formas de la violencia en tiempos de crisis: una villa miseria en el conourbano bonaerense. En: ISLA, Alexandro Raúl y MÍGUEZ, Daniel (Orgs.). Heridas urbanas: Violencia delictiva y transformaciones sociales en los noventa. Buenos Aires: Ed. de las ciencias, p. 35$70,2003$. 
TELLO WEISS, Mariana. Historias de (des)aparecidos. Un abordaje antropológico sobre los fantasmas en torno a los lugares donde se ejerció la represión política. Revista Estudios de Antropología Social. Buenos Aires, v. 1, n. 1, p. 33-49, enero/julio 2016.

TOBÓN, Marco. Los sueños como instrumentos etnográficos. Revista de Antropología Iberoamericana. Madrid, v. 10, n. 3, p. 331-353, 2015.

VIANNA, Adriana. El mal que se adivina: Policía y minoridad en Río de Janeiro, 1910-1920. Buenos Aires: AD-HOC; Facultad de Derecho-UBA, 2007. 198p.

Recibido en: 10 de julio de 2018

Aprobado en: 21 de diciembre de 2018 